\title{
O livro didático na Educação de Jovens e Adultos (EJA): ferramenta para certificação ou para um processo de ensino e aprendizagem significativo?
}

\author{
Janine Marta Pereira Antunes da Silva \\ CEFET - MG
}

\author{
Ana Maria Nápoles Villela \\ CEFET/MG
}

\begin{abstract}
Resumo
Analisamos, nesta pesquisa, uma coleção de livros didáticos destinada à EJA. Ancorando-nos na ideia defendida por Coscarelli (2009) de que todo texto é um hipertexto, investigamos, por meio da análise de aspectos organizacionais (boxes, links, elementos multimodais etc.) e textos verbais e não-verbais, se a hipertextualidade constitutiva do material está em consonância com a documentação oficial da EJA.
\end{abstract}

Palavras Chave: hipertextualidade, livro didático, EJA

\begin{abstract}
In this paper, we analyze a collection of course books designed for Youth and Adult Education. Anchored in the idea defended by Coscarelli (2009) that all texts are hypertexts, we analyzed the organizational aspects (boxes, links, multimodal elements and other), verbal texts and non-verbal texts of the books. The purpose of this was to investigate whether the hypertextuality in the material is in line with the official Youth and Adult Education documentation.

Keywords: hypertextuality, course book, Youth and Adult Education
\end{abstract}

\section{INTRODUÇÃO - EJA: EDUCAÇÃO PARA CERTIFICAÇÃO OU PARA TRANSFORMAÇÃO?}

A história da Educação de Jovens e Adultos (EJA) é marcada por embates políticos, momentos de ruptura e inadequação de políticas públicas e práticas pedagógicas. Tal contexto mostra-nos que, até ser concebida como modalidade de ensino da Educação Básica Nacional, conforme prevê o artigo $2^{\circ}$ da Lei de Diretrizes e Bases da Educação Nacional - LDBEN nº 9.394/ 96, lutas e enfrentamentos populares foram necessários, em favor do acesso e permanência do público jovem e adulto nas salas de aula brasileiras.

Conforme descrito pela proposta curricular para EJA (2002), jovens e adultos dessa modalidade vêm de classes sociais pobres e não tiveram acesso à educação na 
idade própria, na maioria das vezes pela necessidade de entrar precocemente para o mercado de trabalho. De acordo com o Relatório global sobre a aprendizagem e educação de adulto ${ }^{i}$

\begin{abstract}
a quantidade e a qualidade da oferta de oportunidades de educação de adultos são, obviamente, determinadas pelo ambiente social e econômico geral, mas a prioridade conferida a esta atividade é uma questão de vontade política. $\mathrm{O}$ financiamento público para a educação de adultos é fortemente influenciado pela ideologia política e distribuição da riqueza na sociedade (...) a maioria dos excluídos das oportunidades de educação de adultos geralmente pertence a segmentos já marginalizados da população (UNESCO, p. 57).
\end{abstract}

Tanto o relatório global da Organização das Nações Unidas para a Educação, Ciência e Cultura (UNESCO), como a proposta curricular fazem menção à necessidade de adequação de práticas pedagógicas, reformulação de políticas públicas, não marginalização do alunado jovem e adulto e investimentos na formação docente, entre outros importantes apontamentos.

Há expressiva produção acadêmica nesse campo, a exemplo a Associação Nacional de Pós Graduação e Pesquisa em Educação (ANPED), que possui grupos de trabalho específicos para a Educação de Pessoas Jovens e Adultas (GT18). A discussão sobre as deficiências na oferta educacional ao aluno EJA chega a alcançar, inclusive, território internacional: as Conferências Internacionais sobre Educação de Jovens e Adultos, CONFINTEA's ${ }^{\text {ii, }}$, uma série de reuniões internacionais organizadas pala UNESCO, com o objetivo de discutir questões relativas aos desafios da EJA, são um importante exemplo dessa mobilização. Na próxima sessão do trabalho apresentaremos reflexões sobre a qualidade do livro didático para EJA, um dos problemas enfrentados por quem atua nesta modalidade de ensino.

\footnotetext{
${ }^{i}$ A publicação deste relatório global sobre a aprendizagem e educação de adultos (GRALE) marca a contribuição oportuna da $6^{\text {a }}$ Conferência Internacional sobre Educação de Adultos (VI CONFINTEA), realizada (...) em Belém. Com base nos relatórios nacionais de 154 estadosmembro, o GRALE analisa tendências, identifica os principais desafios e as melhores práticas, e recomenda um curso de ação para melhorar o escopo da aprendizagem e educação de adultos (UNESCO, 2009, p.8).

ii Ocorrem, geralmente, a cada 12 ou 13 anos, entre seus países membros. Tem como objetivo discutir a educação de adultos e a educação não formal e sua extensão a todos. A I CONFINTEA aconteceu em 1949 na Dinamarca, logo após o término da $2^{\mathrm{a}}$ guerra mundial. Sua temática esteve ligada à busca pela paz e à adaptação dos conteúdos à realidade dos alunos adultos. Em 2009, o Brasil recebeu a VI CONFINTEA, que ocorreu em Belém do Pará e teve como tema: "Vivendo e aprendendo para um futuro viável: o poder da aprendizagem e da educação de adultos". Das CONFINTEA's nascem documentos contendo discussões e a diretrizes que orientam a condução da educação de adultos.
} 


\section{O LIVRO DIDÁTICO E A EDUCAÇÃO DE JOVENS E ADULTOS}

A falta e/ou inadequação de recursos didáticos têm sido apontadas como destaques entre os sérios problemas enfrentados na Educação de Jovens e Adultos. É sabido que, dentre os recursos utilizados nas salas de aula, o livro didático (LD) é um dos que exerce maior influência na prática de ensino brasileira (Brasil, 2002). Por essa razão, é importante refletir sobre a qualidade do material que tem sido levado para as salas de aula da EJA.

No presente trabalho, analisamos uma coleção de livros didáticos destinados ao público jovem e adulto. O objetivo é verificar se o material foi concebido sob a perspectiva da documentação oficial da EJA, ou seja, se atende à concepção de educação presente nesses documentos.

Investigamos se os livros propõem práticas pedagógicas significativas ${ }^{\mathrm{iii}} \mathrm{e}$ adequadas à promoção de um processo de ensino e aprendizagem que prepare o público envolvido para atuar criticamente na sociedade da qual faz parte, sendo capaz de transformá-la; ou se apenas apresentam conteúdo e atividades comuns aos testes de certificação, que não são garantia da aquisição de habilidades e conhecimentos necessários à formação para a cidadania.

Para tanto, partimos da concepção de LD como dispositivo midiático (Klein, 2007), pensando na sua dimensão tecnológica e na hipertextualidade que o constitui.

Com base nos trabalhos de Peraya (1999), Klein expõe uma proposta triádica para o conceito: "O dispositivo aparece como um lugar das interações entre os universos: uma tecnologia; um sistema de relações sociais; um sistema de representações.” (p. 217). O conteúdo do LD vincula-se a determinado currículo, que é construído com base nas relações sociais que se deseja promover entre o público para o qual o documento se destina e seu entorno social. Assim o discurso veiculado pelo LD é mediado pelo que Foucault (1996) denomina "procedimentos de controle", que são personificados, no contexto da Educação, pelo currículo.

\footnotetext{
iii Por práticas pedagógicas significativas entendemos que são aquelas adotadas por professores e editores que levem em conta as peculiaridades do público ao qual se destinam. No caso da EJA, é necessária a produção de aulas e materiais que concebam os alunos como um público diferente daquele de alunos em idade regular, ou seja, que percebam o aluno jovem e adulto traz consigo uma série de conhecimentos adquiridos ao longo de suas trajetórias de vida, geralmente marcadas por muitas dificuldades. Em suas práticas, os profissionais que lidam com EJA devem valorizar os conhecimentos trazidos por esses alunos e promover práticas que aproximem o conhecimento escolar do universo desses sujeitos.
} 
O sistema de representações sociais vinculadas ao LD pode ser identificado conforme conteúdo que apresenta e as práticas pedagógicas que reforça. Por meio deles é possível identificar as representações sobre o público ao qual o material se destina. Desse modo a hipertextualidade constitutiva do LD será um importante indício para se chegar às intenções do "implícito" (Charaudeau, 2009) presente nas situações discursivas, que carregam os mecanismos de controle, de acordo com Foucault.

Para Chartier (2002), a hipertextualidade é tratada como processo que produz relações entre imagens, sons e textos associados não linearmente. O autor fala em "conexões eletrônicas", remetendo- nos ao universo virtual. Entretanto Coscarelli afirma que

(...) definições de hipertexto aplicam-se também a textos que não estão em ambiente digital, pois a presença de títulos, subtítulos, índices, pé de página, as redes causais, as cadeias referenciais entre tantos elementos, que marcam a não linearidade dos elementos do texto, fazem parte de textos de modo geral, não sendo particularidade dos textos em ambientes digitais. Além disso, podemos entender que os links possam ser de vários tipos como notas de pé de página, citações, referências a outros textos e vozes, além de ícones, palavras azuis grifadas, entre outras convenções para indicar links no texto digital. O que reforça minha tese de que todo texto é um hipertexto e toda leitura é um processo hipertextual. (COSCARELLI, 2009, p. 554)

Sob esse ponto de vista, é possível conceber o livro didático como objeto essencialmente hipertextual, já que seus organizadores utilizam fontes diversas de pesquisa, diferentes linguagens, textos diversos e recursos multimodais em sua concepção. Se explorados adequadamente no LD, os elementos hipertextuais tornam-se importante ferramenta para a educação na perspectiva do letramento, como defende a proposta curricular para EJA. Ainda de acordo com o documento,

(...) a EJA deve propiciar a qualidade do processo de ensino e aprendizagem; desse modo, o curso deve ser pensado e planejado de forma a possibilitar o acesso e a permanência do aluno, o que implica necessariamente o desenvolvimento de práticas pedagógicas que valorizem suas experiências e seus conhecimentos prévios e considerem o vínculo entre educação, trabalho e práticas sociais e culturais. (BRASIL, 2002, p. 80)

Não se pode afirmar que apenas o uso de livros didáticos pedagogicamente adequados seja a garantia da formação de cidadãos conscientes e atuantes em espaços sociais diversos. Entretanto, na consciência de que a formação para a cidadania é resultado de um conjunto de determinações da condição social dos alunos, é possível perceber a evidente contribuição da escola e de práticas coerentes ao processo de constituição do sujeito enquanto cidadão (Castanheira \& Costa Val, 2005). 
De acordo com Batista (2005), livros didáticos são o principal meio de escolarização e letramento para grande parte da população brasileira. Por essa razão devem possibilitar a relação entre os conteúdos escolares e os saberes não escolarizados, adquiridos na trajetória de vida dos alunos de EJA. É preciso promover o rompimento das barreiras preconceituosas existentes entre o que se denomina "saberes populares" e "saberes científicos" (Brasil, 2002). Os conhecimentos construídos ao longo da vida devem ser validados e valorizados, sendo os saberes científicos a sistematização de saberes já adquiridos.

Por meio do Programa Nacional do Livro Didático - PNLD, o Estado estabelece um programa de avaliação desses materiais didáticos. Conforme Batista (2005) "A realização da avaliação terminou por resultar numa política do Estado de intervenção não apenas no campo editorial e de controle de sua produção, mas, por meio delas, de intervenção no currículo e de seu controle.” (p. 17). Assim entende-se que interesses políticos manifestam-se, não só nas concepções e rupturas concernentes à EJA, mas também na legitimação do que e como deve ser ensinado.

A avaliação dos livros didáticos e ainda a definição do currículo são mecanismos de controle das classes dominantes que desejam fortalecer as relações de poder e desigualdade predominantes na sociedade capitalista. Sob tal ponto de vista, o currículo torna- se o meio para a concretização de tal dominação. Para a sociedade que se deseja ter, determina-se, por meio do controle das práticas educativas, o homem que se quer formar. Segundo Foucault

\begin{abstract}
A educação pode muito bem ser, de direito, o instrumento graças ao qual todo indivíduo, numa sociedade como a nossa, pode ter acesso a qualquer tipo de discurso; sabemos, no entanto, que a sua distribuição, naquilo que permite e naquilo que impede, ela segue as linhas que são marcadas pelas distâncias, pelas oposições e pelas lutas sociais. Todo o sistema de educação é uma maneira política de manter ou de modificar a apropriação dos discursos, com o saber e os poderes que estes trazem consigo. (...) O que é, no fim das contas, um sistema de ensino senão uma ritualização da fala, senão uma qualificação e uma fixação dos papéis dos sujeitos falantes; senão a constituição de um grupo doutrinal, por difuso que seja; senão uma distribuição e uma apropriação do discurso com seus poderes e seus saberes? (FOUCAULT, 1996, p. 43)
\end{abstract}

Sob a perspectiva de Foucault, pode-se perceber os elementos hipertextuais presentes no LD como indícios dos tipos de relações que se deseja reforçar. As ideias que nos orientaram para a compreensão da noção de hipertextualidade são exploradas na seção seguinte. 


\section{O CONCEITO DE HIPERTEXTUALIDADE E SUA APLICAÇÃO AO CURRÍCULO DA EJA}

Para Charaudeau\&Maingueneau (2014) a noção de hipertextualidade foi introduzida por Genette (1982) para o estudo da literatura, mas o conceito pode se estender a outros tipos de discurso. As relações estabelecidas entre um texto B (hipertexto) e um texto A (hipotexto) caracterizam o conceito de hipertextualidade. Nesse sentido hipertexto seria a derivação de outro texto já existente.

Segundo Ribeiro (2006), o surgimento do conceito de hipertexto pode ser atribuído a Vannevar Bush e Theodore Nelson. Bush imaginou uma máquina que pudesse funcionar criando elos entre as informações, como se fossem nós, "encruzilhadas virtuais e informacionais". Nelson teria nomeado o objeto imaginado por Bush como hipertexto, um "sistema mecânico em que as informações se ligassem por meio de links navegáveis”. Assim, o leitor acessaria partes desse sistema na ordem que proporcionasse uma organização mental conforme seus interesses, livre das especificidades de outros ambientes textuais. Seria uma forma personalizada de realizar leituras e escrita.

Tal sistema funcionaria a exemplo da mente humana enquanto trabalha nos processos de leitura. A mente é capaz de selecionar, hierarquizar, realizar esquemas e estabelecer redes semânticas, conforme defende Levy (1996), o que justifica afirmar que todo processo de leitura é hipertextual.

Pode-se associar a ideia de hipertexto à noção de polifonia buscada por Bakthin, já que o hipertexto abre possibilidades para o diálogo entre vozes diferentes, para a negociação de sentidos e construção coletiva do pensamento (Ramal, 2000).

O objeto livro didático, independente do conteúdo que veicule, possui um caráter hipertextual, à medida que possui “múltiplas facetas”, como define Bittencourt

\footnotetext{
(...) ora é visto como um produto cultural, ora como mercadoria ligada ao mercado editorial e, como tal, sujeito à lógica do sistema capitalista; outras vezes é visto como suporte de conhecimentos e de métodos das várias disciplinas curriculares e, sobretudo, como veículo de valores ideológicos ou culturais. (BITTENCOURT, 2004, p. 01)
}

Importante é refletir sobre quais os tipos de valores são veiculados pelo LD, para reforçar qual o tipo de concepção de sujeito aluno EJA, em favor de qual concepção de educação. É essa a análise proposta na próxima seção deste trabalho. 


\section{A HIPERTEXTUALIDADE CONSTITUTIVA DO LD PARA EJA: UMA PROPOSTA DE APRENDIZAGEM SIGNIFICATIVA?}

O objeto de análise desta pesquisa é a Coleção EJA Moderna: Educação de Jovens e Adultos: anos finais do ensino fundamental. O conjunto é composto por quatro livros didáticos. Cada LD é constituído pelos seguintes conteúdos: Arte, Ciências, Espanhol, Geografia, História, Inglês, Língua Portuguesa e Matemática. Cada livro destina-se a uma etapa dessa modalidade de ensino $\left(6^{\circ}, 7^{\circ}, 8^{\circ}\right.$ e $9^{\circ}$ ano). O material foi concebido no ano de 2013 e destina-se a alunos EJA do $2^{\circ}$ segmento do Ensino Fundamental. O $2^{\circ}$ segmento compreende a etapa anteriormente denominada " $5^{\mathrm{a}}$ a $8^{\mathrm{a}}$ série", redefinida como " 60 ao $9^{\circ}$ " ano do ensino fundamental.

Para a análise, os conteúdos foram agrupados por áreas de conhecimento, a saber: Linguagens (Língua Portuguesa, Língua Estrangeira, Arte), Ciências Humanas (História e Geografia), Matemática e Ciências da Natureza.

Elegemos oito itens para análise da hipertextualidade constitutiva dos LD's de cada área de conhecimento:

1. diversidade e formas de abordagem de gêneros textuais;

2. diversidade temática: relevância dos temas;

3. presença de textos autênticos;

4. diversidade no contexto cultural;

5. colaboração para a capacidade de desenvolvimento da cidadania;

6. relações entre conhecimentos prévios dos alunos com os conteúdos abordados;

7. exploração dos aspectos organizacionais do LD: elementos multimodais, links, boxes etc.;

8. presença de sugestões de leituras e/ ou atividades em outros livros ou outros dispositivos.

Por meio de tais categorias de análise, identificamos as (im)pertinências da utilização da hipertextualidade para os fins aos quais se destina a Educação de Jovens e Adultos. 


\section{A hipertextualidade presente nos livros didáticos da área de Linguagens}

O material didático preparado para a área de linguagens é o que apresenta maior ocorrência de elementos hipertextuais. Há grande diversidade de gêneros, tais como: poema, lenda, crônica, anúncio publicitário, letra de música, notícia, tira, memórias literárias, conto, entrevista, resumo, seminário, reportagem, debate, artigo de opinião, charge, rótulo de informação nutricional, dentre outros. Entretanto, gêneros próximos dos alunos, que fazem parte de suas práticas cotidianas, não foram abordados, tais como: receita culinária, bula de remédio, currículo, entre outros.

Esse fato não invalida o trabalho com os demais gêneros, mas uma prática pedagógica que aborde gêneros textuais recorrentes no dia a dia dos alunos tende a tornar o aprendizado mais significativo e próximo de sua realidade, o que seria interessante ponto de partida para o trabalho com gêneros "mais complexos" como o artigo de opinião, por exemplo.

Há o uso de imagens soltas, não contextualizadas, na proposta de produção de textos. A ausência de contexto desvincula o texto de suas condições sócio- discursivas de produção. Cria-se, com isso, a ideia de que tais textos estão presentes no material apenas para que o aluno tenha uma ferramenta em que possa aplicar o conhecimento adquirido e sistematizado, ignorando-se a potencialidade discursiva que o trabalho teria num contexto autêntico. A seguir um exemplo de atividade em que o texto é abordado fora de suas condições de produção:

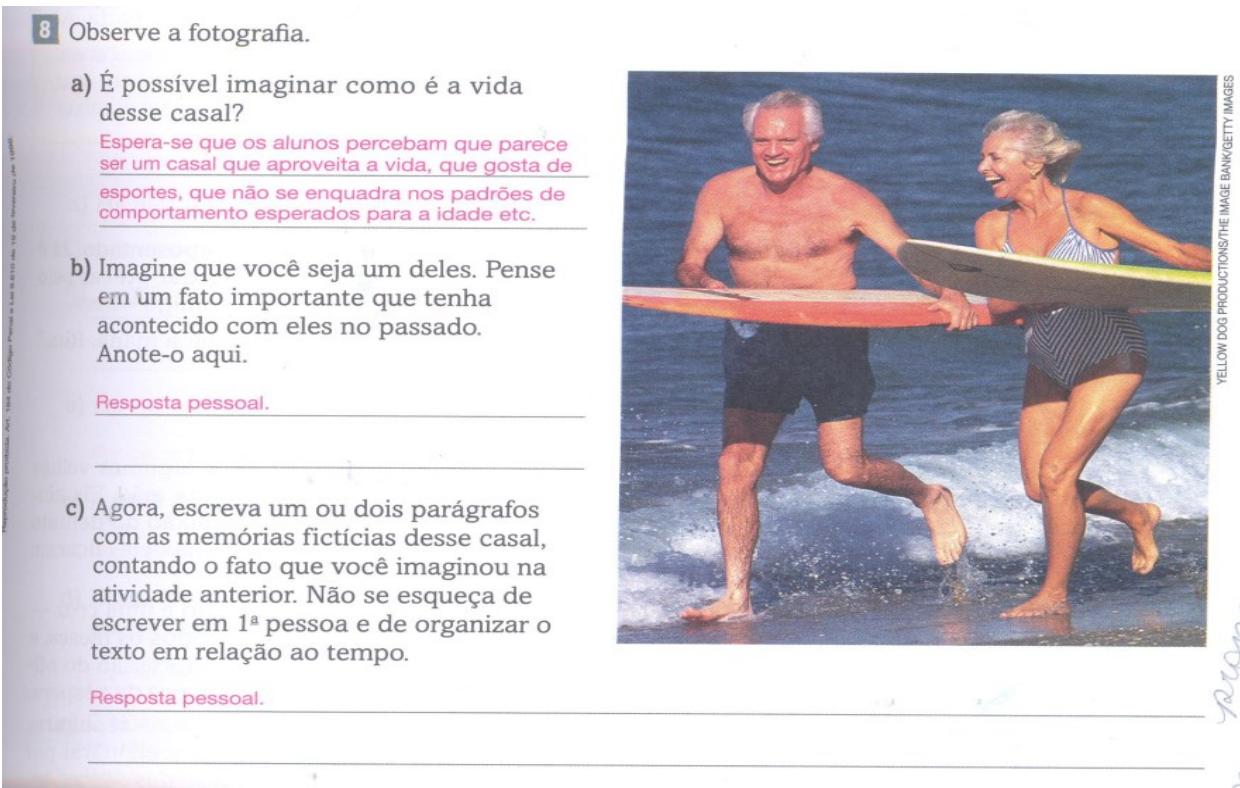

Imagem 1: Atividade do livro de língua portuguesa do $7^{\circ}$ ano 
Alguns textos são apresentados e seguidos de uma seção denominada "Para conhecer o contexto", entretanto nesse espaço, um box apresenta um pequeno texto, uma "mini biografia", que informa o nome do autor do texto apresentado, sua origem e profíssão, eximindo-se de situar sócio historicamente as condições de produção daqueles discursos. É sabido que a linguagem não pode ser estudada fora desse aspecto, pois os processos que a constituem são histórico sociais.

Para as atividades propostas para o conteúdo de língua estrangeira é recorrente o uso de textos não autênticos, deixando de lado a dimensão social do uso da língua. $\mathrm{Na}$ unidade intitulada "Inglês e o mercado de trabalho" muito pouco é explorado sobre a utilização do idioma em situações reais de comunicação, ou sobre a importância do idioma como facilitador nas relações sociais e profissionais, por exemplo. A unidade limita-se a apresentar o vocabulário referente às profissões, posições e cargos.

No conteúdo relativo à Arte, a linguagem não verbal é utilizada ao longo de toda a obra. Fotografias e pinturas são recursos recorrentes na representação de diferentes momentos históricos da trajetória da arte no Brasil. Entretanto não são desenvolvidas atividades que permitam o estabelecimento de "conexões" entre a arte e as demais áreas de conhecimento e suas práticas cotidianas.

\section{Hipertextualidade nas Ciências Humanas}

No material produzido para o conteúdo de Geografia são utilizados gêneros textuais como mapas, fotografias representando a fauna e a flora brasileira, gráficos, charges, poema, tabelas, reportagem, letra de música; fotografias de lugares ou acontecimentos específicos do Brasil.

No conteúdo selecionado para o $6^{\circ}$ ano - ao se abordar a questão das divisões existentes no país: divisão por regiões, divisão por unidades de relevo, divisão por tipos de clima - passa- se a ideia de fragmentação de lugar e de espaço, como se houvesse o isolamento de cada uma das regiões e os acontecimentos se processassem de forma desarticulada. É evidente que os alunos devem conhecer as divisões do território brasileiro, mas é necessário que ele seja levado a construir as relações que se estabelecem entre elas, de modo a se alcançar a noção de unicidade.

O trabalho com diferentes linguagens enriquece a prática pedagógica e possibilita que o aluno tenha a possibilidade de interagir com elementos próprios da Geografia, como mapas, gráficos, imagens, tabelas. Porém o tipo de atividade deve promover essa 
interação. As práticas propostas no material privilegiam, em sua grande maioria, atividades de leitura e interpretação de textos preparados para o contexto didático, o que em certa medida pode provocar a passividade do leitor, que passa a receptor e reprodutor das informações. Ele deve ser instigado a produzir novos textos a partir dos conhecimentos adquiridos.

Cabe questionar ainda a legitimidade dos conteúdos selecionados. Será significativo para o aluno EJA, partir da observação de imagens de paisagens comuns a uma realidade à qual ele não pertence para identificar o tipo de relevo presente? Que conhecimentos e reflexões deixaram de ser explorados?

Para o trabalho desenvolvido no âmbito do conteúdo de História são utilizados, ao longo do LD, gêneros como linha do tempo, pinturas, fotografia, mapas, tabela, charges, reportagens, biografia, gráfico, cartaz. No material transparece a visão de ensino de história factual e linear. Assim não é viabilizada pelo LD a abordagem do cotidiano, da história local e questões regionais.

As atividades propostas, embora utilizem elementos hipertextuais como a presença de charges e gráficos, entre outros, na maioria das vezes relacionam-se a trechos do texto didático, nos quais os alunos podem encontrar prontas as respostas. Algumas atividades incentivam a realização de pesquisas relativas ao tema abordado no texto de referência da unidade de trabalho do $\mathrm{LD}$, mas não se propõem atividades que promovam, efetivamente, a construção de uma visão crítica e o reconhecimento das inflexões de determinados fatos históricos em nossa sociedade.

Inseridos no corpo do texto, há a presença de boxes contendo o glossário ou pequenos textos relativos ao tema abordado no texto principal, assim como imagens de marcos históricos da história do Brasil.

O LD em questão não propicia a associação e visão crítica de fatos históricos com a realidade vivenciada hoje pelos alunos. Por exemplo, ao abordar o período $d a$ República das Oligarquias (1894-1930), é mencionada a prática do voto de cabresto. Os alunos deveriam ser levados a refletir sobre a atualidade dessa prática nos dias de hoje, e suas consequências para a sociedade como um todo.

\section{Hipertexto e Ciências Naturais}

$\mathrm{Na}$ área de Ciências Naturais são apresentados gêneros do tipo gráfico, linha do tempo, reportagem, charge, tabela, esquemas mesclando linguagem verbal e não verbal, 
pinturas, gráfico, mapa, cartaz de divulgação, fotografias de elementos da fauna e flora brasileira, de fatos ocorridos no Brasil e de situações cotidianas.

Embora o material aborde temáticas relevantes como a relação entre consumo e meio ambiente, muito se perde na possibilidade de associação ao cotidiano dos alunos e na construção de uma consciência crítica, ao se privilegiar, novamente, atividades que se restringem à leitura e interpretação dos textos referência das unidades temáticas.

A organização dos conteúdos acompanha a sequenciação tradicional dos livros didáticos, com a divisão de assuntos de modo estanque. Fenômenos relativos ao universo da Física e da Química, por exemplo, são abordados apenas no $9^{\circ}$ ano.

Alguns textos propostos abordam assuntos relacionados às ciências naturais utilizando-se da interdisciplinaridade com as ciências humanas e a Matemática. Entretanto a inadequação de determinadas atividades não potencializam o entrecruzamento de tais conhecimentos pelos alunos. O capítulo que trabalha a questão do sedentarismo no Brasil, por exemplo, propõe uma atividade em que são apresentadas quatro imagens de pessoas praticando diferentes atividades físicas. As imagens não são contextualizadas e aos alunos é solicitado que escrevam uma frase para definir o conjunto de imagens. Aos alunos poderia ter sido apresentado outro texto relativo ao tema, um texto autêntico. Além do trabalho com o gênero, poderia ser-lhes possibilitado estabelecerem vínculos com a sua própria realidade, o que dificilmente aconteceria com a mera exploração de imagens isoladas e fora de contexto. Segue um exemplo:

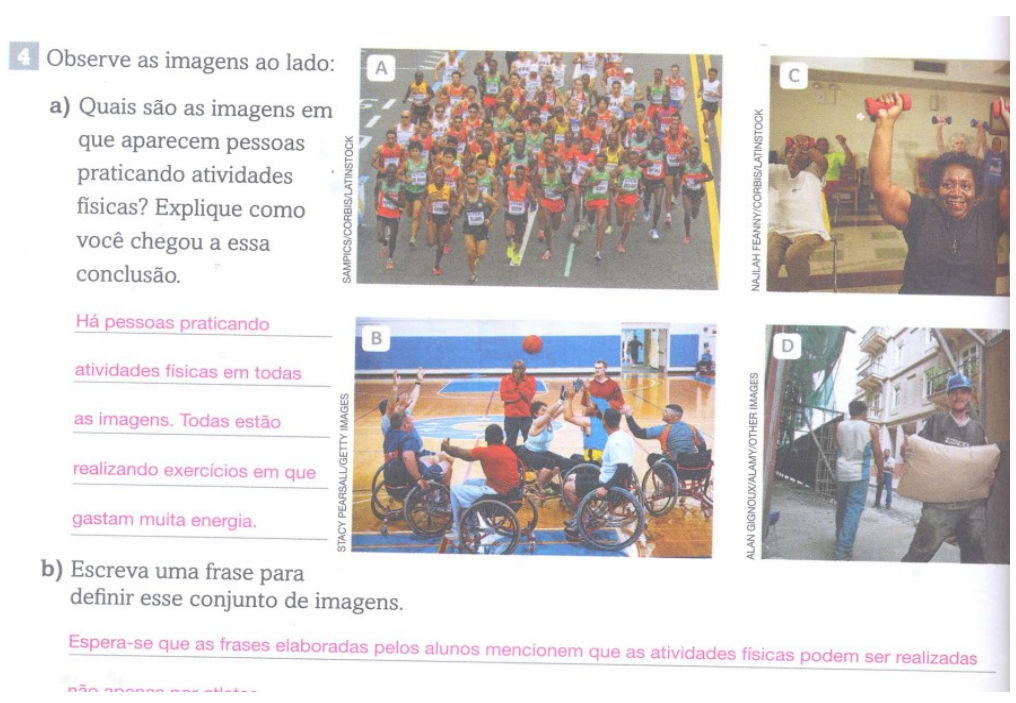

Imagem 2: atividade do livro de ciências naturais 


\section{A hipertextualidade constitutiva do livro didático de Matemática}

O LD de Matemática é composto por textos como tabelas, gráficos, tira, material publicitário, pinturas, mapa, placa de trânsito, reportagem, receita culinária, artigo de revista, conta de luz, fotografias de situações específicas e de objetos da nossa cultura (tipos de moradia), cujo formato pode ser associado a figuras geométricas.

A riqueza de gêneros textuais é um ponto positivo na constituição do LD, porém tais gêneros não são abordados do ponto de vista de seu uso social. Em geral são utilizados apenas como "objeto" motivador do problema.

No conteúdo de Matemática, é importante que se ofereçam ao aluno ferramentas para a interpretação de problemas. Ele precisa ser capaz de compreender os enunciados, usar informações dadas, estabelecer relações e interpretar resultados. Com isso esperase que ele esteja apto a lidar com situações novas e variadas (Brasil, 2002). Para tanto o ideal é que o aluno seja exposto à resolução de situações reais, e não a enunciados elaborados para fins didáticos, que the exijam apenas a habilidade de aplicar e reproduzir conhecimentos pela imitação de fórmulas e esquemas pré-estabelecidos.

Foi possível observar que, grande parte dos problemas propostos, sobretudo para alunos do $5^{\circ}$ e $6^{\circ}$ ano, não apresentam textos autênticos, como retratado a seguir:

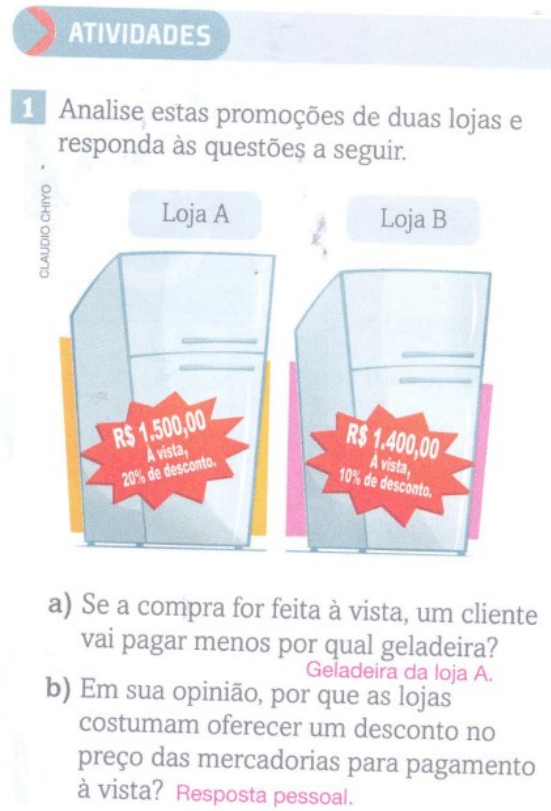


É necessário reafirmar que alunos jovens e adultos passam por situações fora do contexto escolar como efetuar e decidir sobre pagamentos, decidir sobre situações de trabalho, decidir sobre a educação dos filhos, dentre tantas outras que aparecem em seu dia a dia. Para isso analisam situações, prevêem opções, fazem conjeturas sobre possíveis resultados, argumentam, contra argumentam, chegam a conclusões e comunicam tais conclusões. Enfim, resolvem problemas (Brasil, 2002). É a esse cenário que as práticas pedagógicas oferecidas pelo material didático devem favorecer.

Sob essa perspectiva, volta a surgir o questionamento sobre a legitimação e relevância dos conteúdos oferecidos.

\section{HIPERTEXTUALIDADE CONSTITUTIVA DOS LIVROS DIDÁTICOS PARA EJA: ALGUMAS CONSIDERAÇÕES}

Consciente de que a diversidade de gêneros textuais presente na coleção constituise em ponto positivo na concepção da obra, reforço que mais positivas ainda deveriam ser as atividades propostas para o trabalho com tais gêneros. É sabido que "(...) o texto, concebido como um objeto autônomo, fora de suas condições de produção/circulação, não existe, e que é na ação social de sua leitura/produção que ele se atualiza" (Nascimento \& Paiva, 2006, p.165).

Nessa perspectiva, mais urgente se faz a aproximação do aluno e o gênero em tela nas atividades propostas, conscientizando-o de seu uso social, tornando possível que ele crie "elos hipertextuais mentais", que sejam capazes de "acessar mentalmente outros textos engatilhados" que os remetam à sua realidade e à interdisciplinaridade existente entre os conteúdos oferecidos a ele. A ideia de conhecimento fragmentado que a divisão dos conteúdos em disciplinas reforça, também pode ser desmistificada se os elementos hipertextuais forem utilizados adequadamente.

$\mathrm{O}$ material oferecido à EJA apresenta outros aspectos positivos como a diversidade temática e exploração do contexto cultural do aluno nas unidades de trabalho do LD. Ao aluno é possibilitado o contato com textos que falam sobre saúde, mercado de trabalho, questões ambientais, dentre outros temas relevantes para a essa modalidade de ensino.

Os quatro volumes apresentam a mesma divisão por disciplina. Eles subdividemse em duas unidades, que são compostas por dois capítulos cada. O tema de cada 
unidade é o mesmo para cada uma das disciplinas, o que, se bem explorado, poderia ser um facilitador para reforçar a ideia de conhecimento como um todo.

No que tange aos aspectos organizacionais dos LD's, contou-se com a presença de boxes informativos, sobretudo nas ciências naturais e humanas. Os boxes apresentam informações que permitem o estabelecimento de links com o texto referência da unidade de trabalho.

Ao final de cada compartimento dedicado a uma disciplina específica, há uma seção intitulada Indicações de livros, sites e filmes. Nessa seção, são indicados outros dispositivos midiáticos que abordam temas afins aos assuntos presentes nas unidades e capítulos do LD. A disposição dessa seção ao final de cada compartimento rompe com a ideia de instantaneidade no estabelecimento de elos com outras leituras, e de nãolinearidade que constituem o conceito de hipertexto, e distancia o aluno do processo interdiscursivo que poderia se estabelecer com novas leituras.

$\mathrm{Na}$ organização do LD, não são utilizados elementos que nos remetam ao universo virtual, ao qual a noção de hipertexto está fortemente ligada. Tal fato pode contribuir para a construção da representação de um aluno que não tenha acesso ao contexto virtual e de LD que não se empenha em proporcionar essa aproximação. Isso pode ser reforçado pelo box que aparece ao lado de uma sugestão de atividade presente no conteúdo da área de linguagens, pelo uso dos modalizadores caso e se:

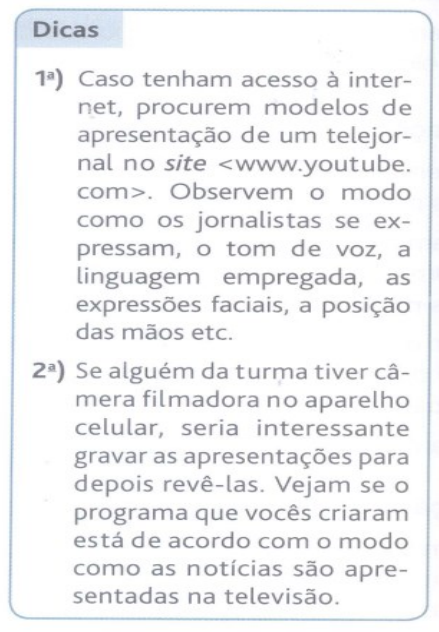

Imagem 4: Box presente no livro de língua portuguesa do $7^{\circ}$ ano

Saber utilizar as tecnologias da informação e da comunicação em seus diferentes suportes é condição necessária para a inserção social de todas as pessoas. Para tal, o livro didático deve provocar a proximidade do aluno com esse universo, que está 
presente em seu dia a dia (uso de caixas eletrônicos, emissão de documentos e pagamentos online etc.). De acordo com a proposta curricular para a EJA

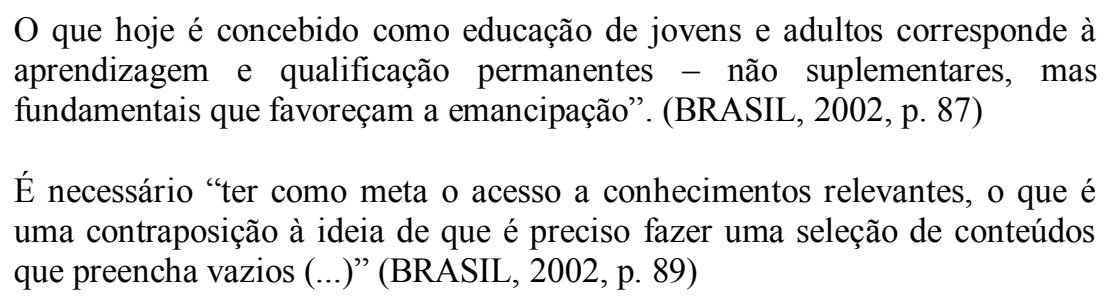

Com base na análise de elementos hipertextuais na estrutura dos livros didáticos eleitos para a pesquisa, foi possível perceber que muito ainda deve ser feito para que se alcance o status de adequação do material didático às reais necessidades do público da EJA, descritas na documentação oficial.

\section{CONSIDERAÇÕES FINAIS}

O mundo exige pessoas hábeis no trato das diferentes esferas da vida: trabalho, família, participação social e política, atividades de lazer e cultura, etc. Para isso é necessária uma atuação crítica, responsável e transformadora, que é possível quando o sujeito se descobre construtor de seus próprios conhecimentos e se torna capaz de atuar no seu mundo cultural e social e transformá-lo.

A escola e todo seu aparato didático pedagógico, dentre os quais se destaca o livro didático, deve oferecer possibilidades que fomentem uma construção realista e significativa da realidade.

É necessário romper com os lugares comuns circundantes da EJA e seu público. Uma prática pedagógica significativa e inclusiva respalda um processo de aprendizagem em que o sujeito consegue se ver livre das amarras impostas pelos mecanismos de controle que permeiam a sociedade e seus discursos.

Como afirma Paulo Freire (1996), autor no qual se baseia a proposta curricular da EJA, os educandos devem se transformar em reais sujeitos da construção e reconstrução do saber ensinado. Eles devem ser capazes de ir além das páginas do livro didático para escreverem suas próprias histórias, conscientes de seu papel na sociedade. O livro didático, a escola, o professor devem contribuir para essa escritura.

É claro que não depende apenas da adequação do livro didático para que essa mudança se concretize. Para isso seria necessário recriar a EJA, reinventar o currículo, 
redesenhar as relações sociais, processos que certamente levariam muito tempo para se concretizarem.

Então que comecemos pelo principal: criar dentro da sala de aula um ambiente propício para o desenvolvimento de sujeitos fazedores de seu próprio mundo.

\section{REFERÊNCIAS}

ARROYO, Miguel. Educação de Jovens e Adultos: um campo de direitos e de responsabilidade pública. In: SOARES, Leôncio; GIOVANETTI, Maria Amélia; GOMES, Nilma Lino (Orgs.). Diálogos na educação de jovens e adultos. Belo Horizonte: Autêntica, 2005.

BARROS, J. S. O texto na era do hipertexto. Academos. Revista Eletrônica da FIA, vol.III, $n^{\circ} 3$, jul a dez de 2007. ISSN: 1809-3604.

BATISTA, A. A. G. Política de materiais didáticos, do livro e da leitura no Brasil. In: Brasil. Ministério da Educação. Materiais didáticos: escolha e uso. Boletim 14. Agosto, 2005. TV Escola, Salto para o Futuro.

BITTENCOURT, Circe. Em foco: História, produção e memória do livro didático. Educação e Pesquisa - Revista da Faculdade de Educação da USP. São Paulo, Universidade de São Paulo, v. 30, nº 3, set- dez/ 2004, p. 564- 565.

BRASIL. Ministério da Educação e do Desporto. Secretaria de Educação Fundamental. Proposta Curricular para a educação de jovens e adultos: segundo segmento do ensino fundamental: $5^{\mathrm{a}}$ a $8^{\mathrm{a}}$ série: introdução/ Secretaria de Educação Fundamental, 2002.

CHARTIER, R. Os desafios da escrita. Trad. Fulvia M.L. Moreto. São Paulo: UNESP, 2002.

COSCARELLI, C. V. Textos e hipertextos: procurando o equilíbrio. In: ARAÚJO, Júlio César (org). Linguagem em (Dis) curso. Palhoça, Santa Catarina: PPGCL/ UNISUL, v.9, no 3, p. 549-564, set/ dez, 2009.

COSTA VAL, Maria da Graça \& CASTANHEIRA, Maria Lúcia. Cidadania e ensino em livros didáticos de alfabetização e de língua portuguesa (de $1^{\mathrm{a}}$ a $4^{\mathrm{a}}$ série. In: COSTA VAL, Maria da Graça; MARCHUSCHI, Beth (orgs). Livros didáticos de língua portuguesa: letramento e cidadania. Belo Horizonte: Ceale; Autêntica, 2005.

COSTA, S. R. Leitura e escrita de hipertextos: implicações didático- pedagógicas e curriculares. In: FREITAS. M. T. A., COSTA, S. R. (orgs). Leitura e escrita de adolescentes na internet e na escola. Belo Horizonte: Autêntica, 2006.

FOUCAULT, Michel. A ordem do discurso. Edições Loyola: São Paulo, 1996. 
FREIRE, Paulo. Pedagogia da Autonomia: saberes necessários à prática educativa. São Paulo: Paz e Terra, 1996.

KLEIN, Otávio José. A gênese do conceito de dispositivo e sua utilização nos estudos midiáticos. Estudos em Comunicação nº 1, 215-231. Abril de 2007

NASCIMENTO, Milton, PAIVA, V.L.M.O. Texto, hipertexto e a (re) configuração de (con) textos. In: LARA, G .M. P. (org). Lingua(gem), texto e discurso, v.1: entre a reflexão e a prática. Rio de Janeiro: Lucerna; Belo Horizonte: FALE/ UFMG, 2006.

RAMAL, A. C. Ler e escrever na cultura digital. Porto Alegre: Revista Pátio, ano 4, $\mathrm{n}^{\mathrm{o}}$ 14, agosto- outubro/ 2000, p. 21-24.

RIBEIRO, Ana Elisa. Leituras sobre hipertexto trilhas para o pesquisador. Anais do XI Simpósio Nacional de Letras e Linguística e I Simpósio Internacional de Letras e Linguìstica, Uberlândia, Nov/ 2006.

SILVA, J. O. , BARROS- GOMES, J. S. Textualização do discurso: o livro didático como hipertexto. Revista Espaço Literário. Edição jul/dez, 2012. Disponível em http://www.encontrosdevista.com.br/jul_dez12.html.

UNESCO. Relatório global sobre aprendizagem e educação de adultos. Brasília: 2010, $156 \mathrm{p}$.

\section{AS AUTORAS}

Janine Marta Pereira Antunes da Silva é professora de língua inglesa na Educação de Jovens e Adultos da rede municipal de Betim e mestranda no Programa de Pós Graduação em Estudos de Linguagens do CEFET/ MG

E-mail: janinemarta@hotmail.com

Ana Maria Nápoles Villela é Professora Titular do Programa de Pós-Graduação em Estudos de Linguagens do CEFET/ MG.

E-mail: anapoles@uol.com.br 
J.M.P.A.Silva \& A.M.N.Villela/Pesquisas em Discurso Pedagógico 2016.1 